The Free Internet Journal for Organic Chemistry
Paper

Arkivoc 2020, part viii, 58-69

\title{
Preparation of solid solution and crystal-glass composite consisting of stable phenoxyl radical and its phenol analogue
}

\author{
Taku Kamoto, Lyu Xinwen, Junro Yoshino, and Naoto Hayashi*
}

Graduate School of Science and Engineering, University of Toyama, 3190 Gofuku, Toyama 930-8555, Japan

Email: nhayashi@sci.u-toyama.ac.jp

Received 08-30-2020

Accepted 10-09-2020

Published on line 11-03-2020

\section{Abstract}

Evaporation of mixed solution of 2,4,6-tris(4-tert-butylphenyl)phenoxyl $\mathbf{1}_{\mathrm{M}}$ and its phenol analogue $\mathbf{1}_{\mathrm{OH}}$ yielded a solid solution (III), where $\mathbf{1}_{\mathrm{OH}}: \mathbf{1}_{\mathrm{M}}=0.70: 0.30$, which was isomorphic to crystal of $\mathbf{1}_{\mathrm{OH}}$ (II). In contrast, slow evaporation of $\mathbf{1}_{\mathbf{M}}$ concomitant with gradual decomposition giving $\mathbf{1}_{\mathrm{OH}}$ yielded crystal-glass composite (IV) consisting of $\mathbf{1}_{\mathrm{OH}}: \mathbf{1}_{\mathrm{M}}$ with a molar ratio of $0.40: 0.60$. The outer crystal region of IV was attributed to solid solution of $\mathbf{1}_{\mathrm{OH}}$ and $\mathbf{1}_{\mathrm{M}}$, while the inner glassy region to amorphous consisting of $\mathbf{1}_{\mathrm{M}}$ and its dimer $\mathbf{1}_{\mathrm{D}}(\mathrm{I})$.

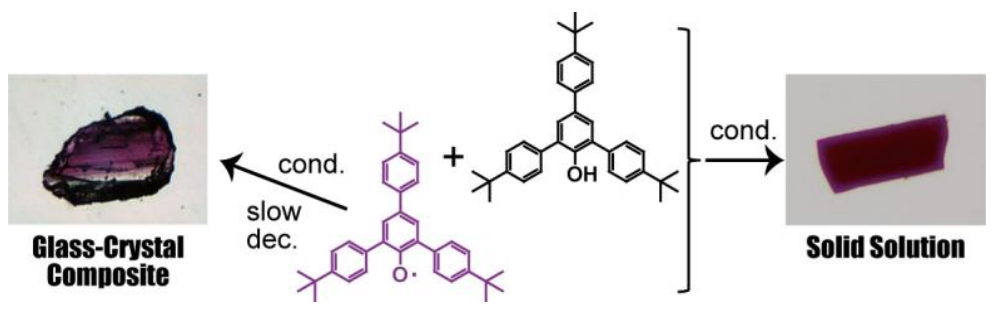

Keywords: Solid solution, crystal-glass composite, stable phenoxyl radical, amorphous 


\section{Introduction}

The most common molecular solids are single-component crystals, but there are many other types of molecular solids, which include non-crystalline solids (amorphous or glass, liquid crystals, and plastic crystals) and multi-component solids (cocrystals, eutectic mixtures, and solid solutions). Owing to their unique structure and properties, these molecular solids have attracted much attentions. ${ }^{1,2}$ Above all, solid solutions are particularly important because the design of solid-state properties is facile. Generally, prediction of structure and properties of molecular solids is difficult. This is because properties of molecular solids are determined by both intrinsic character of the molecule and packing structure. While the former can be predicted rather precisely by theoretical calculations, the latter is essentially unpredictable because it alters readily by responding sharply to the change in molecular size, shape, and participating intermolecular interactions. This is a big issue to design the molecular solids possessing desired structure and/or properties.

On the other hand, the aforementioned principle determining packing structure also indicates that, when the molecules have virtually identical size, shape, and intermolecular interactions, they should give isostructural crystals and/or solid solutions. Indeed, it is well known that molecules bearing chloro group and their methyl analogue often give isostructural crystals. This relationship is referred to as "chloro-methyl rule" ${ }^{3,4}$ Pairs of benzene and pyrazine, benzene and thiophene, and thiophene and selenophene moieties are also known to be interchangeable. ${ }^{5}$ It may be noted that, although they have similar size and shape, $\mathrm{C}-\mathrm{H}$ and $\mathrm{C}-\mathrm{F}$ groups are less likely interchangeable due to the presence of $\mathrm{C}-\mathrm{H} \cdots \mathrm{F}-\mathrm{C}$ interaction or $\mathrm{F} / \pi$ repulsion. ${ }^{6}$ Pairs of compounds giving isostructural crystals are likely to afford solid solutions, which are isostructural to crystals of the individual components mostly. At this point, properties of the solid solution can be reasonably predicted based on the crystal structure of individual components and difference in their properties, thus solid solution can be a powerful tool to design the molecular solids possessing desired structure and/or properties.

Although phenoxyl radicals have rather similar size and shape to its phenol analogue, they do not necessarily give solid solutions. This should be because these compounds have different solubility, the difference of $\mathrm{O}$. of phonoxyl and $\mathrm{OH}$ group of phenol in size and shape is small but significant, and $\mathrm{O} \cdot$ and $\mathrm{OH}$ groups participate in different intermolecular interactions (for example, $\mathrm{OH}$ group can behave as a hydrogen bond donor, while $\mathrm{O}$. cannot). In contrast, since different behavior of $\mathrm{O}$. and $\mathrm{OH}$ groups become ignorable by the presence of the substituent, phenoxyl radicals that are sterically stabilized are prone to form solid solutions with their phenol analogue. For example, galvinoxyl and hydrogalvinoxyl can yield a solid solution with a molar ratio of $4: 96{ }^{7}$ This solid solution showed remarkable magnetic property, in which intermolecular exchange interaction was ferromagnetic in contrast to antiferromagnetic character of the pure galvinoxyl crystal. ${ }^{7}$ Stabilized phenoxyl radicals are widely used to develop functional magnetic materials ${ }^{8-11}$ and redox materials including battery, ${ }^{12,13}$ and in these fields solid solutions may play an important role to control the magnetic properties. 
<smiles>CC(C)(C)C1=CC(=Cc2cc(C(C)(C)C)c(O)c(C(C)(C)C)c2)C=C(C(C)(C)C)C1=O</smiles>

galvinoxyl<smiles>CC(C)(C)C1=CC(=Cc2cc(C(C)(C)C)c(O)c(C(C)(C)C)c2)C=C(C(C)(C)C)C1=O</smiles>

hydrogalvinoxyl

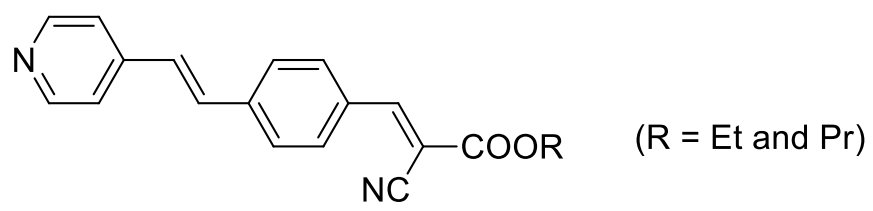

ethyl and propyl $\alpha$-cyano-4-[2-(4-pyridyl)ethenyl]cinnamates<smiles>OC1(c2cc3sccc3s2)c2ccccc2C(O)(c2cc3sccc3s2)c2ccccc21</smiles>

trans-9,10-dihydroxy-9,10-bis(thieno[3,2b]thienyl)-9,10-dihydroanthracene<smiles>OC1(c2cc3sccc3s2)c2ccccc2C(O)(c2cc3ccsc3s2)c2ccccc21</smiles>

trans-9,10-dihydroxy-9-(thieno[2,3b]thienyl)-10-(thieno[3,2-b]thienyl)9,10-dihydroanthracene

Although most solid solutions are isostructural with crystals of their individual components, there are a small number of exceptions, where both crystal structures of individual components and solid solutions are not identical. For example, although packing structures of ethyl and propyl $\alpha$-cyano-4-[2-(4pyridyl)ethenyl]cinnamates were virtually identical, that of their solid solution was different. ${ }^{14}$ Crystal structures of trans-9,10-dihydroxy-9,10-bis(thieno[3,2-b]thienyl)-9,10-dihydroanthracene, and its solid solution with trans-9,10-dihydroxy-9-(thieno[2,3-b]thienyl)-10-(thieno[3,2-b]thienyl)-9,10-dihydroanthracene were isomorphic, crystal structure of the latter itself was different. ${ }^{15}$ Furthermore, crystal structures of benzoic acid, 4-fluorobenzoic acid, and their solid solution were all different. ${ }^{16}$ These facts indicate that relationship between crystal structure of individual components and their solid solution should be more complicated than generally considered.

In the present paper, we have the attention to a stabilized phenoxyl radical, 2,4,6-tris(4-tertbutylphenyl)phenoxyl $\mathbf{1}_{\mathrm{M}}$. $\mathbf{1}_{\mathrm{M}}$ owns a unique characteristic that it can yield both amorphous solid (I) consisting of $\mathbf{1}_{M}$ and its equilibrium dimer $\mathbf{1}_{D}$ (where $\mathbf{1}_{M}: \mathbf{1}_{D}=0.09: 0.91$ ) and crystal consisting solely of $\mathbf{1}_{D}$ depending on solidification solvents. ${ }^{17}$ Since there was no report on solidification behaviour of combination of such unique phenoxyl radicals and their phenol analogues, solidification behaviour of $\mathbf{1}_{\mathbf{M}}$ and its phenolic analogue ( $\left.\mathbf{1}_{\mathrm{OH}}\right)$ has been examined herein. 

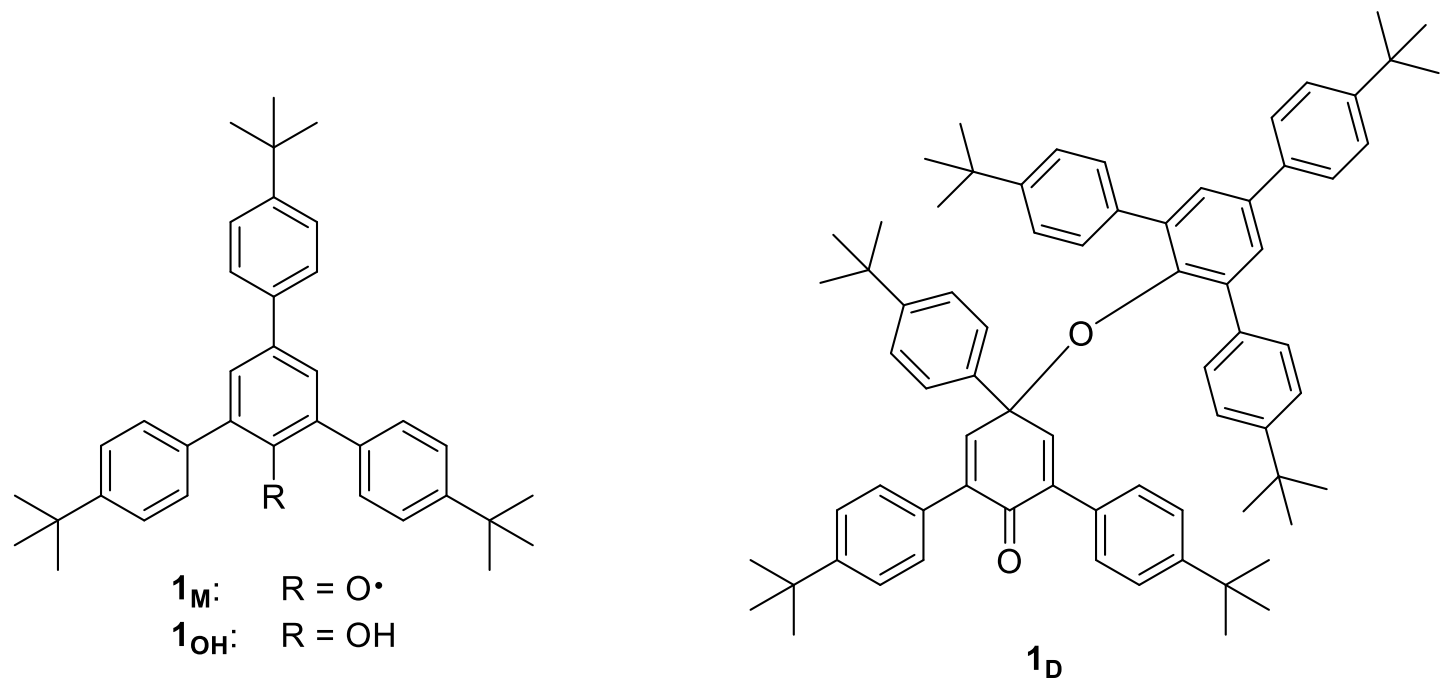

\section{Results and Discussion}

First, crystal structure of $\mathbf{1}_{\text {он }}$ itself (II) was determined. II was obtained by recrystallization from ethyl acetatehexane solution as colorless prism. When 1:1 mixture of $\mathbf{1}_{\mathrm{OH}}$ and $\mathbf{1}_{\mathrm{M}}$ in acetone were evaporated, homogeneously purple crystal (III) was yielded (See Graphical Abstract). The $\mathbf{1}_{\mathrm{OH}}: \mathbf{1}_{\mathrm{M}}$ ratio in III was determined by the titration experiment using hydroquinone to be $0.70: 0.30$. A preliminary experiment showed that $1_{M}$ was degraded in acetone by $3 \%$ in $1 \mathrm{~h}$ likely due to the abstraction of $\alpha$-hydrogen atom of acetone. This indicates that the stoichiometric ratio of $1_{\mathrm{OH}}$ and $\mathbf{1}_{\mathrm{M}}$ should have been no longer $1: 1$ when III was precipitated. The higher $\mathbf{1}_{\mathrm{OH}}$ content ratio than that in the initial solution should be due to the reaction of $\mathbf{1}_{\mathrm{M}}$ with the solvent. Also, the lower solubility of $\mathbf{1}_{\mathrm{OH}}$ should be responsible, by which $\mathbf{1}_{\mathrm{OH}}$ precipitated prior to $\mathbf{1}_{\mathrm{M}}$. Similar purple crystal was yielded from solutions where $\mathbf{1}_{\text {Он }}$ contained more than $\mathbf{1}_{\mathrm{M}}$; on the contrary, even when solutions where $\mathbf{1}_{\mathrm{OH}}$ contained much less than $\mathbf{1}_{\mathrm{M}}$ were evaporated, no purple crystal containing $\mathbf{1}_{\mathrm{M}}$ more than $\mathbf{1}_{\mathrm{OH}}$ but a mixture of I and II was yielded.

In contrast, on very slow evaporation of ethereal solution of $\mathbf{1}_{\mathrm{M}}$ over one week, apparently crystalline solid (IV) was obtained. IV consisted of a purple inner region and an apparently colourless outside region (See Graphical Abstract). When IV was dissolved in benzene and oxidized by using $\mathrm{K}_{3}\left[\mathrm{Fe}(\mathrm{CN})_{6}\right]$ under basic condition, the resultant solution consisted solely of $\mathbf{1}_{\mathrm{M}}$ and $\mathbf{1}_{\mathrm{D}}$, as similar to benzene solution of $\mathbf{I}$. When IV was reduced by using hydroquinone in benzene, $\mathbf{1}_{\mathrm{OH}}$ was obtained as a single product. These results indicate that the purple and colorless component in IV was attributed to $\mathbf{1}_{\mathbf{M}}$ and $\mathbf{1}_{\mathrm{OH}}$, respectively. Titration experiment revealed that IV contained $\mathbf{1}_{\mathrm{OH}}$ less than $\mathbf{1}_{\mathrm{M}}$, a stoichiometric ratio of which was $0.40: 0.60 . \mathbf{1}_{\mathrm{OH}}$ should have arisen by reaction of $1_{M}$ with solvent likely due to the abstraction of $\alpha$-hydrogen atom of ether. Indeed, when ethereal solution of $\mathbf{1}_{\mathrm{M}}$ in a sealed flask was left for two months, $\mathbf{1}_{\mathrm{M}}$ was thoroughly deteriorated into $\mathbf{1}_{\mathrm{OH}}$.

X-ray structure of II is depicted in Figures $1 \mathrm{a}$. II consists of one independent $\mathbf{1}_{\mathrm{OH}}$ molecule, whose $\mathrm{OH}$ group was disordered. The occupancy factors of 01,02 , and 03 were $29 \%, 54 \%$, and $17 \%$, respectively. There are two possible reasons for the presence of the disorder. First, the molecular structure of $\mathbf{1}_{\mathrm{OH}}$ has pseudo $3-$ fold symmetry, which would give the packing energy to be rather close whichever disorder site the $\mathrm{OH}$ group occupies. Second, $\mathrm{OH}$ group cannot form intermolecular hydrogen bond at any disorder site due to the vicinal aryl substituents. This is confirmed by the following facts. In the X-ray structure, any pair of $\mathbf{1}_{\mathrm{OH}}$ molecules has 
no shorter intermolecular $\mathrm{O} \cdots \mathrm{O}$ contact than sum of van der Waals radii. Also, in the infrared spectrum of II, $\mathrm{O}-\mathrm{H}$ vibration was observed at $3542 \mathrm{~cm}^{-1}$ as a sharp peak (Figure S2).

X-ray analysis of III revealed that it was isomorphic to II (Figure 1b). The O. group was also disordered, and the occupancy factors of 01,02 , and 03 were 33\%, 48\%, 19\% respectively, which were similar to those of II. Although two oxygen atoms which were of $\mathrm{OH}$ and $\mathrm{O}$. groups, respectively, were not observed separately, III can be regarded to as a solid solution, because all C-O bonds were essentially shorter in the X-ray structure than the corresponding ones in II. Indeed, C-O bond lengths in III were 1.385(8) A for C11-01, 1.366(6) $\AA$ for C13-02, and 1.400(12) $\AA$ for C15-03, while they were 1.433(11) $\AA$, 1.398(6) $\AA$, and 1.404(13) $\AA$ in II, respectively. It is known that $\mathrm{C}-\mathrm{O}$ bond length in phenoxyl radical (1.25 $\AA$ for $\mathrm{PhO}$ - as a calculated value $)^{18}$ is by more than $0.1 \AA$ shorter than standard length of phenolic $\mathrm{C}-\mathrm{O}$ bond $\left(1.37 \AA\right.$ ),${ }^{19,20}$ because of delocalization of unpaired electron on the oxygen atom to the benzene ring, which gives rise to increase a higher double-bond character of the $\mathrm{C}-\mathrm{O}$ bond. Given the fact, it is reasonably considered that the observed shorter $\mathrm{C}-\mathrm{O}$ bonds are attributed to an averaged structure of $\mathbf{1}_{\mathrm{OH}}$ and $\mathbf{1}_{\mathrm{M}}$, and III was a solid solution consisting of $\mathbf{1}_{\mathrm{OH}}$ and $\mathbf{1}_{\mathrm{M}}$.

Table 1. Crystallographic parameters of II-IV

\begin{tabular}{|c|c|c|c|}
\hline & $\begin{array}{c}\text { II } \\
\left(1_{\mathrm{OH}}\right)\end{array}$ & $\begin{array}{c}\text { III } \\
\left(\mathbf{1}_{\mathrm{OH}}: \mathbf{1}_{\mathrm{M}}=70: 30\right)\end{array}$ & $\begin{array}{c}\text { IV } \\
\left(\mathbf{1}_{\mathrm{OH}}: \mathbf{1}_{\mathrm{M}}=40: 60\right)\end{array}$ \\
\hline Molecular Formula & $\mathrm{C}_{36} \mathrm{H}_{42} \mathrm{O}$ & $\mathrm{C}_{36} \mathrm{H}_{42} \mathrm{O}$ & $\mathrm{C}_{36} \mathrm{H}_{41} \mathrm{O}$ \\
\hline Molecular Weight & 490.69 & 490.69 & 490.69 \\
\hline Crystal System & orthorhombic & orthorhombic & orthorhombic \\
\hline Space Group & Pbca (no. 61) & Pbca (no. 61) & Pbca (no. 61) \\
\hline$a / \AA$ & $23.785(14)$ & $23.71(2)$ & $23.849(14)$ \\
\hline$b / \AA$ & 24.885(19) & $24.866(13)$ & 24.993(6) \\
\hline$c / \AA$ & $9.82(2)$ & $9.699(6)$ & $9.798(4)$ \\
\hline$\alpha /^{\circ}$ & 90 & 90 & 90 \\
\hline$B /^{\circ}$ & 90 & 90 & 90 \\
\hline$\gamma /{ }^{\circ}$ & 90 & 90 & 90 \\
\hline$V / \AA^{3}$ & $5810(13)$ & $5720(7)$ & $5840(4)$ \\
\hline$Z$ & 8 & 8 & 8 \\
\hline$T / \mathrm{K}$ & $200(2)$ & $200(2)$ & $200(2)$ \\
\hline$D_{\mathrm{c}} / \mathrm{g} \mathrm{cm}^{-3}$ & 1.122 & 1.140 & 1.114 \\
\hline$R 1(I>2 \sigma(I))$ & 0.0851 & 0.0698 & 0.0806 \\
\hline$w R 2$ (all data) & 0.2317 & 0.2061 & 0.2292 \\
\hline CCDC number & 1895027 & 1895028 & 1895078 \\
\hline
\end{tabular}

X-ray structure of IV was also isomorphic to those of II and III (Figure 1c). Crystal parameters of II-IV are shown in Table 1 for comparison. Oxygen atoms were again disordered with occupancy factors of 34\%, $50 \%$, and $16 \%$ for 01,02 , and 03 , respectively. IV had seemed to be a composite crystal ${ }^{21-23}$ consisting of $\mathbf{1}_{\mathrm{OH}}$ and $\mathbf{1}_{M}$ in the outer and inner regions, respectively. This hypothesis was, however, denied by the fact that

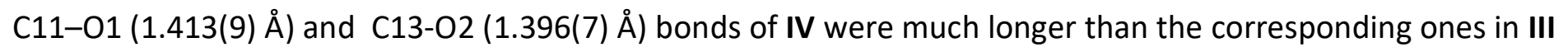
and comparable or slightly shorter than those in II, although $\mathbf{1}_{\mathbf{M}} / \mathbf{1}_{\mathrm{OH}}$ ratio in IV is larger than that in III (C15-O3 bond lengths of II-IV cannot be compared meaningfully because they have large errors). Considering that solid solution character of III is responsible for their shorter $\mathrm{C}-\mathrm{O}$ bond, $\mathbf{1}_{\mathbf{M}}$ may contribute the X-ray structure of IV 
slightly. Consequently, it is reasonably considered that most of $\mathbf{1}_{\mathbf{M}}$ should be present in the inner region of IV as an amorphous solid, although the outer region may contains only slight part.

(a)

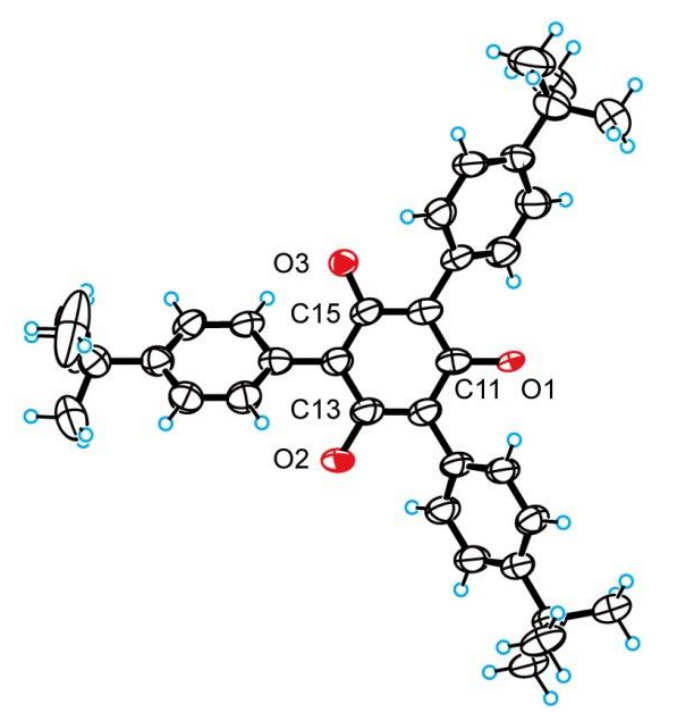

(b)

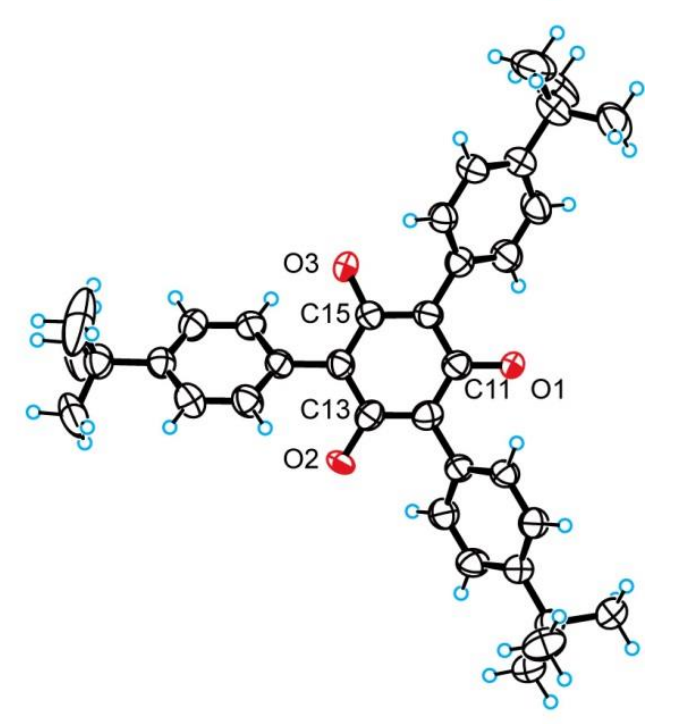

(c)

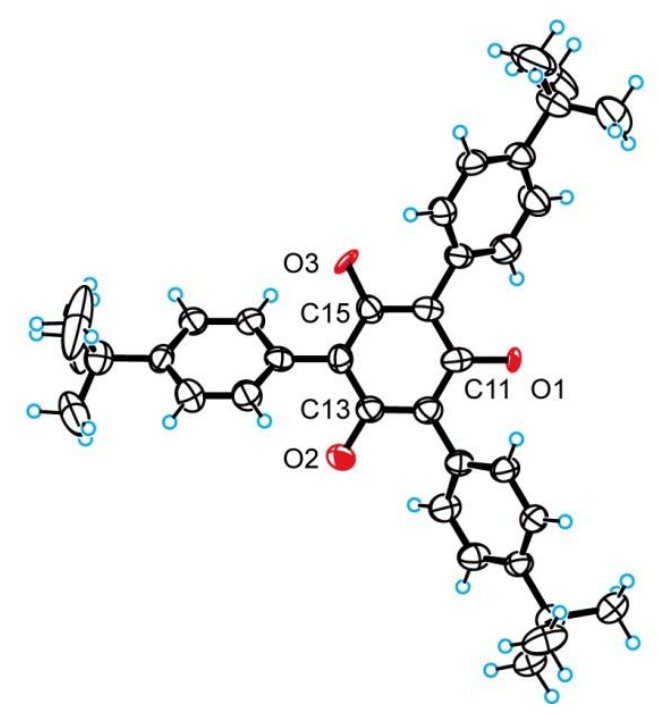

Figure 1. X-ray structures of II (a), III (b) and IV (c). Some oxygen and carbon atoms are labelled. 
Structure of III and IV was supported by means of differential scanning calorimetry (DSC) analysis (Figure 2). First, I was found to give an exotherm at $T_{\text {peak }} 143^{\circ} \mathrm{C}\left(T_{\text {onset }} 124{ }^{\circ} \mathrm{C}\right)$ on heating. The products of the thermolysis were $\mathbf{1}_{\text {он }}(44 \%), 2$ (55\%), and a small amount (3\%) of benzofuran derivative 3 (Figure 3). It was previously reported that $\mathbf{1}_{\mathrm{OH}}$ and $\mathbf{2}$ were obtained in thermolysis of an equilibrium solution of $\mathbf{1}_{\mathrm{M}}$ and $\mathbf{1}_{\mathrm{D}}$ in tetrachloroethylene at $124{ }^{\circ} \mathrm{C} .{ }^{24}$ Although 3 was not referred to in ref. 24 , we found that 3 was obtained in the pyrolysis at the higher temperature $\left(\sim 180^{\circ} \mathrm{C}\right)$ in tetrachloroethylene. When it was heated, II simply melted at $T_{\text {melt }} 268^{\circ} \mathrm{C}$ without decomposition.

On heating of III, an endotherm was found not around $140^{\circ} \mathrm{C}$ but at $T_{\text {peak }} 257^{\circ} \mathrm{C}\left(T_{\text {onset }} 246{ }^{\circ} \mathrm{C}\right)$. By NMR analysis, the product was mostly $\mathbf{1}_{\mathrm{OH}}(95 \%)$ concomitant with a small amount of $\mathbf{2}(2 \%)$ and $\mathbf{3}(3 \%)$. Since III is a solid solution, intermolecular hydrogen abstraction of $\mathbf{1}_{\mathbf{M}}$ yielding the principal product $\left(\mathbf{1}_{\mathrm{OH}}\right)$ should be difficult to occur therein. Thus, it is most likely that III melted around $T_{\text {peak }}$ (which was by $11{ }^{\circ} \mathrm{C}$ lower than the melting point of $\mathrm{II}, 268^{\circ} \mathrm{C}$ ), and consequently (or simultaneously) the thermolysis occurred. In contrast, on heating of IV, an exotherm was observed at $T_{\text {peak }} 136{ }^{\circ} \mathrm{C}\left(T_{\text {onset }} 117^{\circ} \mathrm{C}\right)$. The products contained $\mathbf{1}_{\mathrm{OH}}(73 \%)$ and $\mathbf{2}(27 \%)$, and no $\mathbf{3}$ was yielded. It is noteworthy that the yields of $\mathbf{2}$ in the thermolyses of IV and I were even higher than that in III. In conjunction with similar $T_{\text {onset }}$ in the thermolyses of I and IV, the thermolysis of IV appeared to proceed in the inner region initially. Since the inner region of IV is attributable to amorphous I and the outer region to crystal II, IV should be regarded as a crystal-glass composite. The fact that IV consisted of I was further supported by comparison of diffuse reflectance spectra of I, III, and IV (Figure 4). Diffuse reflectance spectra of I and IV appeared to be virtually identical, in which the longest wavelength absorption maxima $\left(\lambda_{\max }\right)$ were observed commonly at $564 \mathrm{~nm}$, while $\lambda_{\max }$ was by $9 \mathrm{~nm}$ shifted hypsochromically in that of III.

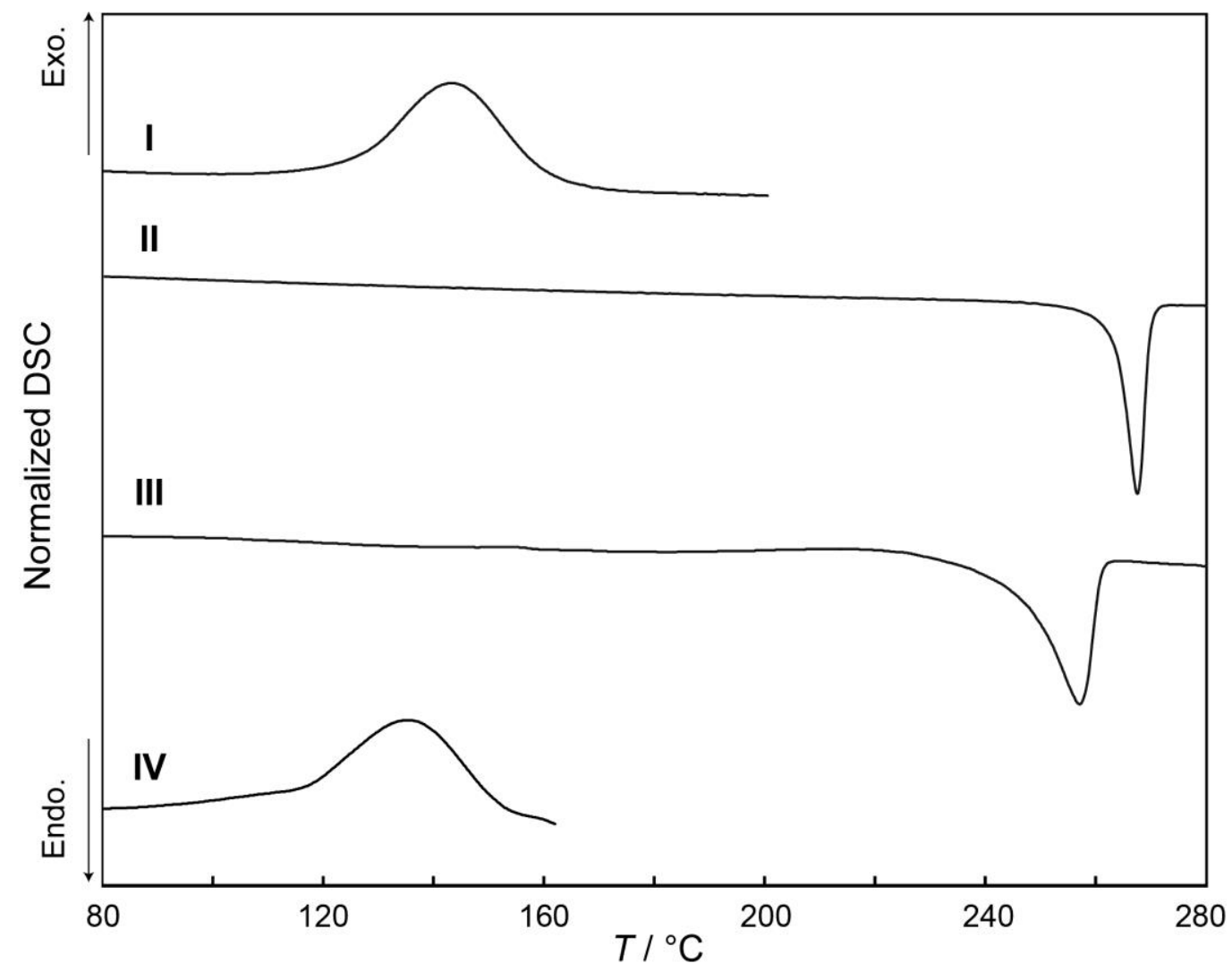

Figure 2. DSC curves of I-IV. Samples ( 3 $\mathrm{mg}$ ) were heated at $5{ }^{\circ} \mathrm{C} \mathrm{min}^{-1}$. 


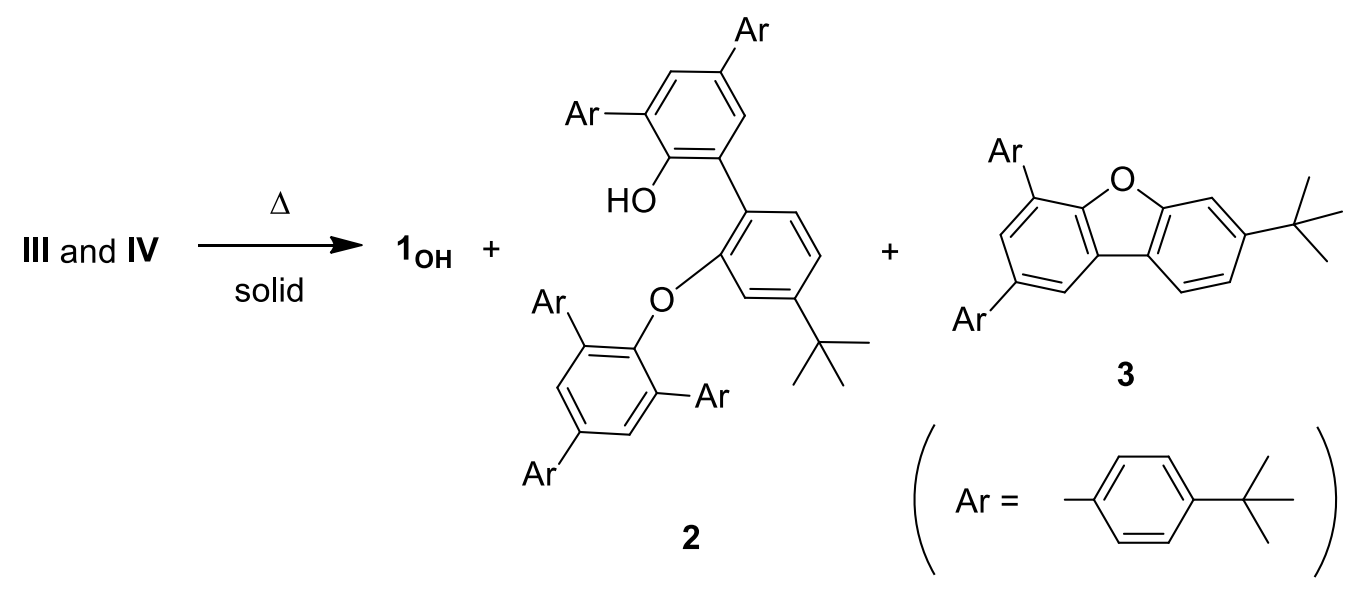

Figure 3. Products of thermal decomposition of III and IV.

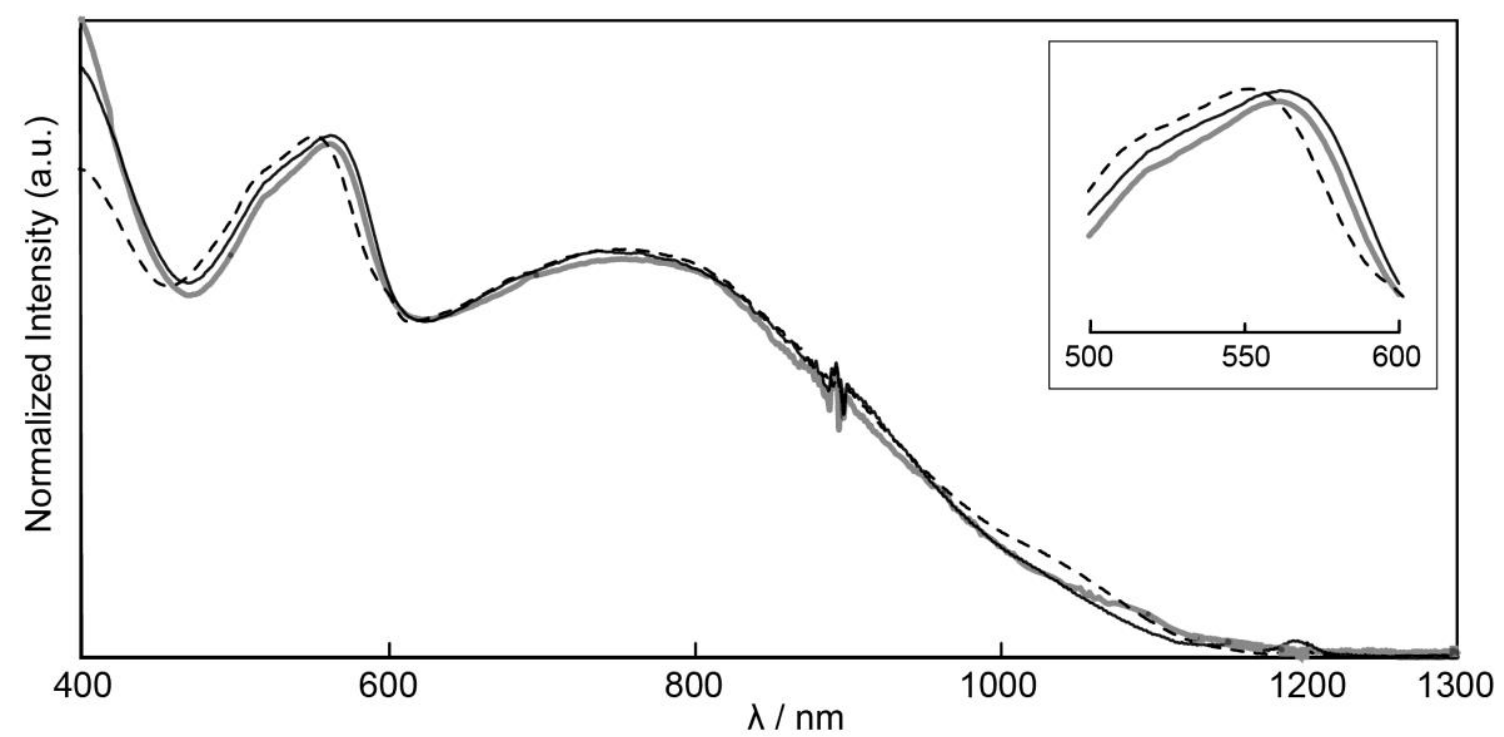

Figure 4. Diffuse reflectance spectra of I (black solid), III (black dotted), and IV (gray bold). (inset) An expansion of the range of 500 to $600 \mathrm{~nm}$.

\section{Conclusions}

While evaporation of acetone solutions of phenoxyl radical $\mathbf{1}_{\mathbf{M}}$ and phenol $\mathbf{1}_{\text {oH }}$ yield amorphous (I) and crystal (II), respectively, evaporation of mixed acetone solution of $\mathbf{1}_{\mathbf{M}}$ and $\mathbf{1}_{\mathrm{OH}}$ yielded solid solution III, which is isomorphic to II. When $\mathbf{1}_{\mathrm{M}}$ was contained more than $\mathbf{1}_{\mathrm{OH}}$, acetone solution gave a mixture of I and II, while ethereal solution yielded crystal-glass composite IV bearing purple inner region and apparently colorless outer region. Phenoxyl C-O bonds were observed to be slightly shorter in X-ray structure of IV as compared to the corresponding bonds in that of II, indicating that the colorless region may be a solid solution containing a small amount of $\mathbf{1}_{\mathbf{M}}$. A crystal-glass composite character of IV was confirmed by analyzing thermal decomposition products and the diffuse reflectance spectra of I-IV. The inorganic crystal-glass composites have been extensively studied recently because they have high potential for luminescent and photo-functional materials, $^{25-27}$ although studies on organic crystal-glass composites were scarce. In this regard, the present study may be a path-breaking work to develop noble organic luminescent materials. Studies on effect of 
solvent in the generation of IV by microscopic analysis on the surfaces and interfaces and examination of distribution of $\mathbf{1}_{\mathrm{M}}$ are currently underway.

\section{Experimental Section}

General. Ethyl acetate and hexane was used as purchased. Acetone was dried over Drierite ${ }^{(R)}$, then distilled under an inert argon atmosphere. Diethyl ether was dried over $\mathrm{CaCl}_{2}$, then distilled over $\mathrm{Na}$ wire under an inert argon atmosphere. DSC measurements were performed on a SHIMADZU DSC-60. Diffuse reflectance spectra were measured on a JASCO V-570 spectrometer. ${ }^{1} \mathrm{H}(600 \mathrm{MHz})$ and ${ }^{13} \mathrm{C}(151 \mathrm{MHz}) \mathrm{NMR}$ spectra were measured on a JEOL JNM-ECP600. Mass spectral analysis was conducted on a JEOL JMS-700V using the FAB ionization method. IR spectra were measured on a JASCO FT/IR-6100 spectrometer.

$\mathbf{1}_{\mathrm{OH}}$ and $\mathbf{1}_{\mathrm{M}}$ were synthesized according to the literature procedure. ${ }^{17,28}$ The purity of $\mathbf{1}_{\mathrm{M}}$ was confirmed as follows. Since $\mathbf{1}_{\mathbf{M}}$ was prepared from $\mathbf{1}_{\mathrm{OH}}$, possible impurities were (unreacted) $\mathbf{1}_{\mathrm{OH}}$ and by-products. Absence of $1_{\mathrm{OH}}$ was confirmed by IR spectrum of I, where no $\mathrm{O}-\mathrm{H}$ vibration was observed at $3542 \mathrm{~cm}^{-1}$ unlike II. Absence of the by-products was confirmed by ${ }^{1} \mathrm{H}$ NMR spectrum of the product from the reaction of I with hydroquinone, in which no signal attributed to $\mathbf{1}_{\mathrm{OH}}$ and quinone was observed (see below).

Preparation of I-IV. Preparation of I-IV was conducted at an ambient temperature. Amorphous solids I was prepared as reported previously. ${ }^{17}$ Crystal II suitable for single-crystal X-ray analysis was obtained by slow evaporation of $5 \mathrm{mg}$ of $\mathbf{1}_{\mathrm{OH}}$ in a mixture of ethyl acetate and hexane $(15 \mathrm{~mL})$ for a few days. Solid solutions III were given when $2 \mathrm{mg}$ of $\mathbf{1}_{\mathrm{OH}}$ and $2 \mathrm{mg}$ of $\mathbf{1}_{\mathrm{M}}$ (as I) was dissolved in distilled acetone (10 $\mathrm{mL}$ ), the $\mathrm{mixed}$ solution was evaporated for $12 \mathrm{~h}$, then the precipitated deep purple needles were filtered from mother solution. Crystal-glass composites IV were given when an Erlenmeyer flask containing a solution of $10 \mathrm{mg}$ of $\mathbf{1}_{\mathrm{M}}$ (as I) in distilled diethyl ether $(5 \mathrm{~mL}$ ) was plugged with a cork stopper then left standing over one week to dryness. After washing carefully, IV was obtained as a platelet or prism.

X-ray analysis of II, III, and IV. Cell dimensions were obtained by a least-squares fit to the settings for 20 carefully centered reflections. The data collected on a RIGAKU AFC-7S diffractometer $\left(\lambda_{\text {Mo, K } \alpha}=0.71069 \AA\right)$ to $2 \theta=55^{\circ}$ gave 6635,6570 , and 6708 independent reflections for II, III, and IV, respectively, and all reflections were used in refinement. Diffraction intensity was not corrected by standard reflections. The data were corrected for Lorentz and polarization factors but no absorption correction was made. The crystal structure was solved by direct methods and Fourier technique (SHELXL-97 ${ }^{29}$ on PC-Linux). All non-hydrogen atoms were refined with anisotropic parameters. All hydrogen atoms except those of $\mathrm{OH}$ groups were placed geometrically with fixed individual displacement parameters $\left[U(H)=1.5\left(C_{\text {methyl }}\right)\right.$ or $\left.1.2\left(C_{\text {phenyl }}\right)\right]$ using a riding model. Hydrogen atoms of $\mathrm{OH}$ groups were not included during refinemt. The site-occupancy factors of $\mathrm{O} 1, \mathrm{O} 2$ and $\mathrm{O} 3(\operatorname{occ}(\mathrm{O} 1), \operatorname{occ}(\mathrm{O} 2)$ and $\operatorname{occ}(\mathrm{O} 3)$, respectively) were refined under conditions that $\operatorname{occ}(\mathrm{O} 1)+\operatorname{occ}(\mathrm{O} 2)+$ $\operatorname{occ}(\mathrm{O} 3)=1, \operatorname{occ}(\mathrm{H} 1)=1-\operatorname{occ}(\mathrm{O} 1), \operatorname{occ}(\mathrm{H} 2)=1-\operatorname{occ}(\mathrm{O} 2)$ and $\operatorname{occ}(\mathrm{H} 3)=1-\operatorname{occ}(\mathrm{O} 3)$.

II. $\mathrm{C}_{36} \mathrm{H}_{42} \mathrm{O}, \mathrm{MW} 490.69$, orthorhombic, Pbca (no. 61), $a=23.785(14), b=24.885(19), c=9.82(2) \AA, \alpha=90^{\circ}, b=$ $90^{\circ}, v=90^{\circ}, V=5810(13) \AA^{3}, Z=8, T=200(2) \mathrm{K}, D_{c}=1.122 \mathrm{~g} \mathrm{~cm}^{-3}, R 1=0.0851(I>2 \sigma(I)), w R 2=0.2317$ (all data). CCDC 1895027.

III. $\mathrm{C}_{36} \mathrm{H}_{42} \mathrm{O}, M W=490.69$, orthorhombic, $P b c a$ (no. 61), $a=23.71(2), b=24.866(13), c=9.699(6) \AA ., \alpha=90^{\circ}, b$ $=90^{\circ}, V=90^{\circ}, V=5720(7) \AA^{3}, Z=8, T=200(2) \mathrm{K}, D_{c}=1.140 \mathrm{~g} \mathrm{~cm}^{-3}, R 1=0.0698(I>2 \sigma(I)), w R 2=0.2061($ all data). CCDC 1895028. 
IV. $\mathrm{C}_{36} \mathrm{H}_{41} \mathrm{O}, M W=489.69$, orthorhombic, $\mathrm{Pbca}$ (no. 61), $a=23.849(14), b=24.993(6), c=9.798(4) \AA, \alpha=90^{\circ}, b$ $=90^{\circ}, V=90^{\circ}, V=5840(4) \AA^{3}, Z=8, T=200(2) \mathrm{K}, D_{c}=1.114 \mathrm{~g} \mathrm{~cm}^{-3}, R 1=0.0806(I>2 \sigma(I)), w R 2=0.2292$ (all data). CCDC 1895078.

Crystallographic data for the structures in this paper have been deposited with the Cambridge Crystallographic Data Centre as supplementary publication. Copies of the data can be obtained, free of charge, on application to CCDC, 12 Union Road, Cambridge CB2 1EZ, UK, (fax: +44-(0)1223-336033 or e-mail: deposit@ccdc.cam.ac.uk).

Thermal deterioration of I, III, and IV. Typical procedure. I (50 mg) in round-bottom flask was heated at $143^{\circ} \mathrm{C}$ ( $=T_{\text {peak }}$ in the DSC analysis) in an oil bath under nitrogen for $2 \mathrm{~h}$. After cooling, the reaction mixture was subjected to NMR analysis to determine the product ratio. Afterwards, the reaction mixture was separated by the column chromatography $\left(\mathrm{SiO}_{2}\right.$, hexane : $\left.\mathrm{CHCl}_{3} 10: 1\right)$ to yield $\mathbf{1}_{\mathrm{OH}}, \mathbf{2}$, and $\mathbf{3}$.

4,6-Bis(4-tert-butylphenyl)-2-\{4-tert-butyl-2-[2,4,6-tris(4-tert-butylphenyl)phenoxy]phenyl\}phenol (2). ${ }^{1} \mathrm{H} N M R$ $\left(\mathrm{CDCl}_{3}\right): \delta 7.65$ (s, 2H, Ar), 7.63 (d, J $8.4 \mathrm{~Hz}, 2 \mathrm{H}, \mathrm{Ar}$ ), 7.59 (d, J $1.8 \mathrm{~Hz}, 1 \mathrm{H}, \mathrm{Ar}$ ), 7.58 (d, J $8.8 \mathrm{~Hz}, 2 \mathrm{H}, \mathrm{Ar}$ ), 7.55 (d, J $8.4 \mathrm{~Hz}, 2 \mathrm{H}, \mathrm{Ar}), 7.48-7.44(\mathrm{~m}, 6 \mathrm{H}, \mathrm{Ar}), 7.34(\mathrm{~d}, J 8.4 \mathrm{~Hz}, 4 \mathrm{H}, \mathrm{Ar}), 7.29$ (d, J $2.6 \mathrm{~Hz}, 1 \mathrm{H}, \mathrm{Ar}), 7.22(\mathrm{~d}, J 8.4 \mathrm{~Hz}, 4 \mathrm{H}$, Ar), 7.04 (d, J $8.1 \mathrm{~Hz}, 1 \mathrm{H}, \mathrm{Ar}$ ), 6.82 (dd, Ja 7.7, $1.8 \mathrm{~Hz}, 1 \mathrm{H}, \mathrm{Ar}), 6.51$ (d, J $1.8 \mathrm{~Hz}, 1 \mathrm{H}, \mathrm{Ar}$ ), 1.39 (s, 9H, tert-Bu), 1.38 (s, 9H, tert-Bu), $1.36\left(\mathrm{~s}, 9 \mathrm{H}\right.$, tert-Bu), $1.20\left(\mathrm{~s}, 18 \mathrm{H}\right.$, tert-Bu), 1.11 (s, 9H, tert-Bu). FT-IR (cm $\left.{ }^{-1}\right): 3542\left(v_{\mathrm{OH}}\right) . \mathrm{MS}$ : $m / z 978\left(\mathrm{M}^{+}\right)$.

2,4-Bis(4-tert-butylphenyl)-7-tert-butyldibenzofuran (3). ${ }^{1} \mathrm{H} \mathrm{NMR}\left(\mathrm{CDCl}_{3}\right): \delta 8.06(\mathrm{~d}, J 1.8 \mathrm{~Hz}, 1 \mathrm{H}, \mathrm{Ar}), 7.92(\mathrm{~d}, J$ $8.1 \mathrm{~Hz}, 1 \mathrm{H}, \mathrm{Ar}), 7.90$ (d, J $1.1 \mathrm{~Hz}, 2 \mathrm{H}, \mathrm{Ar}), 7.79$ (d, J $1.8 \mathrm{~Hz}, 1 \mathrm{H}, \mathrm{Ar}$ ), 7.66 (d, J $8.4 \mathrm{~Hz}, 2 \mathrm{H}, \mathrm{Ar}), 7.65(\mathrm{~d}, J 1.1 \mathrm{~Hz}, 1 \mathrm{H}$, Ar), 7.58 (d, J $8.4 \mathrm{~Hz}, 2 \mathrm{H}, \mathrm{Ar}$ ), 7.52 (d, J $8.4 \mathrm{~Hz}, 2 \mathrm{H}, \mathrm{Ar}$ ), 7.43 (dd, J 7.6, 1.8 Hz, 1H, Ar), 1.42 (s, 9H, tert-Bu), 1.41

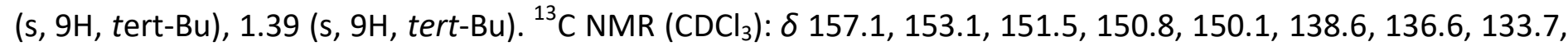
128.5, 127.1, 125.8, 125.7, 125.4, 121.7, 120.4, 120.0, 117.5, 117.5, 108.8, 108.8, 35.3, 34.7, 34.6, 31.6, 31.4, 29.7. MS: $m / z 488\left(\mathrm{M}^{+}\right)$. HRMS ( $\left.m / z\right): 488.3083\left(\mathrm{M}^{+}\right.$, calcd. 488.3079 for $\left.\mathrm{C}_{36} \mathrm{H}_{40} \mathrm{O}\right)$.

\section{Supplementary Material}

The Supplementary Material file can be found in the online version. It contains experimental details of titration experiment of III and IV and solvolysis of $1 \mathrm{M}$ in acetone, the IR spectrum of II and ${ }^{1} \mathrm{H}$ and ${ }^{13} \mathrm{C} \mathrm{NMR}$ spectra of $\mathbf{2}$ and $\mathbf{3}$.

\section{References}

1. Desiraju, G. R.; Vittal, J. J.; Ramanan, A. Crystal Engineering. A Textbook. World Scientific: Singapore, 2011.

2. Bond, A. D. CrystEngComm 2007, 9, 833.

https://doi.org/10.1039/B708112J

3. Jones, W.; Theocharis, C. R.; Thomas, J. M.; Desiraju, G. R. J. Chem. Soc., Chem. Commun. 1983, 1443. https://doi.org/10.1039/C39830001443

(b) Desiraju, G. R., Sarma, J. A. R. P. J. Chem. Sci. 1986, 96, 599.

https://doi.org/10.1007/BF02936309

4. Kitaigorodsky, A. I. Molecular Crystals and Molecules, Academic Press: London, 1973.

5. Hinsberg, O. J. prakt. Chem. 1916, 93, 302. 
https://doi.org/10.1002/prac.19160930119

6. Hayashi, N.; Mori, T.; Matsumoto, K. Chem. Commun. 1998, 1905. https://doi.org/10.1039/A803655A

7. Awaga, K.; Sugano, T.; Kinoshita, M. Chem. Phys. Lett. 1986, 128, 587. https://doi.org/10.1016/00092614(86)80679-0

8. Nishide, H.; Kaneko, T.; Nii, T.; Katoh, K.; Tsuchida, E.; Lahti, P. M. J. Am. Chem. Soc. 1996, 118, 9695. https://doi.org/10.1021/ja961721u

9. Xie, C.; Lahti, P. M.; George, C. Org. Lett. 2000, 2, 3417. https://doi.org/10.1021/ol0063407

10. Nishide, H.; Ozawa, T.; Miyasaka, M.; Tsuchida, E. J. Am. Chem. Soc. 2001, 123, 5942. https://doi.org/10.1021/ja002944u

11. Murata, H.; Mague, J. T.; Aboaku, S.; Yoshioka, N.; Lahti, P. M. Chem. Mater. 2007, 19, 4111. https://doi.org/10.1021/cm0711459

12. Suga, T.; Ohshiro, H.; Sugita, S.; Oyaizu, K.; Nishide, H. Adv. Mater. 2009, 21, 1627. https://doi.org/10.1002/adma.200803073

13. Janoschka, T.; Hager, M. D.; Schubert, U. S. Adv. Mater. 2012, 24, 6397. https://doi.org/10.1002/adma.201203119

14. Maekawa, Y.; Kato, S.; Hasegawa, M. J. Am. Chem. Soc. 1991, 113, 3867. https://doi.org/10.1021/ja00010a031

15. Sekiya, R.; Kiyo-oka, K.; Imakubo, T.; Kobayashi, K. J. Am. Chem. Soc. 2000, 122, 10282. https://doi.org/10.1021/ja000788I

16. Yamamoto, N.; Taga, T.; Machida, K. Acta Cryst. 1989, B45, 162. https://doi.org/10.1107/S0108768188012327

17. Hayashi, N.; Ueno, T.; Okamoto, N.; Mori, T.; Sasaki, N.; Kamoto, T.; Yoshino, J.; Higuchi, H.; Uekusa, H.; Tukada, H. Tetrahedron Lett. 2017, 58, 2547. https://doi.org/10.1016/j.tetlet.2017.05.040

18. Tripathi, G. N. R. J. Phys. Chem. A 1998, 102, 2388. https://doi.org/10.1021/ip9808633

19. Hayashi, N.; Sato, K.; Sato, Y.; Iwagami, M.; Nishimura, N.; Yoshino, J.; Higuchi, H.; Sato, T. J. Org. Chem. 2011, 76, 5747. https://doi.org/10.1021/jo200852r

20. Allen, F. H.; Kennard, O.; Watson, D. G.; Brammer, L.; Orpen, A. G.; Taylor, R. J. Chem. Soc., Perkin Trans. 2 1987, S1.

https://doi.org/10.1039/P298700000S1

21. MacDonald, J. C.; Dorrestein, P. C.; Pilley, M. M.; Foote, M. M.; Lundburg, J. L.; Henning, R. W.; Schultz, A. J.; Manson, J. L. J. Am. Chem. Soc. 2000, 122, 11692.

https://doi.org/10.1021/ja002102v

22. Luo, T.-J. M.; MacDonald, J. C.; Palmore, G. T. R. Chem. Mater. 2004, 16, 4916. https://doi.org/10.1021/cm049121e

23. Dechambenoit, P.; Ferlay, S.; Hosseini, M. W. Cryst. Growth Des. 2005, 5, 2310. https://doi.org/10.1021/cg058011x

24. Dimroth, K.; Tüncher, W.; Kaletsch, H. Chem. Ber. 1978, 111, 264. https://doi.org/10.1002/cber.19781110125

25. Wu, Y.; Xiao, U.; Chen, G.; Liu, C. T.; Lu, Z. Adv. Mater. 2010, 22, 2770. https://doi.org/10.1002/adma.201000482 
26. Nakanishi, T. J. Ceram. Soc. Jpn. 2015, 123, 862. https://doi.org/10.2109/jcersj2.123.862

27. Hou, J.; Ashling, C. W.; Collins, S. M.; Krajnc, A.; Zhou, C.; Longley, L.; Johnstone, D. N.; Chater, P. A.; Li, S.; Coulet, M.-V.; Llewellyn, P. L.; Coudert, F.-X.; Keen, D. A.; Midgley, P. A.; Mali, G.; Chen, V.; Bennett, T. D. Nat. Commun. 2019, 10, 2580.

https://doi.org/10.1038/s41467-019-10470-z

28. Dimroth, K.; Berndt, A.; Perst, H.; Reichardt, C. Org. Synth. Coll. Vol. 1973, 5, 1130. https://doi.org/10.15227/orgsyn.049.0116

29. Sheldrick, G. M. Shelxl-97, Program Package for the Solution and Refinement of Crystal Structures, 1997, University of Gottingen, Germany. 